\title{
Load Frequency Control of a Single Area Power System using Firefly Algorithm
}

\author{
Dillip Khamari ${ }^{1}$, Bikash Kumbhakar ${ }^{2}$, Swagatika Patra ${ }^{3}$, D A Laxmi ${ }^{4}$, Sanjaya Panigrahi ${ }^{5}$ \\ $1,2,3,4,5$ Electrical and Electronics Engineering Department, Vikash Institute of Technology, \\ Bargarh, Odisha, India
}

\begin{abstract}
This paper deals with load frequency control (LFC) of single area power system. A single area non-reheat thermal system is taken in to consideration with proportional plus integral (PI)/ proportional plus integral plus derivative (PID) controller. Firefly algorithm (FA) is suggested for determination of PI/PID controller parameter. The simulation results show that the FA based PI/PID controllers provide a better damping of oscillations compared to those of Gravitational Search Algorithm (GSA) based PI/PID controller and conventional PI controller for the same power system. Lastly robustness analysis is carried out by varying the time constant of turbine, speed governor within the range of $+50 \%$ to $-50 \%$ with respect to their nominal values as well as size and position of step load perturbation to show the robustness of the Firefly Algorithm based PID controller.
\end{abstract}

Keywords - Load frequency control (LFC), Single area power system, Firefly algorithm (FA), proportional plus integral (PI), proportional plus integral plus derivative (PID) controller.

\section{INTRODUCTION}

Load Frequency Control (LFC) is a significant issue in power system operation and control. Since the load demand differs bringing about changes in power system operating point, the frequency deviates from nominal value and moves towards instabilities. The fundamental objective of the LFC is to keep up a zero- system frequency system frequency change by keeping the balance between generation and load demand plus losses. The customary PI controller is generally used to limit the consistent state error of the system frequency in power systems [1,2]. Saikia et al. utilized bacterial foraging optimization technique for multi-area interconnected thermal system. For parameter improvement, a novel integral twofold derivate controller proposed by the creators. It is presumed that this controller gives much preferred unique reaction over different controllers [4].In [5] author were utilized modified classical controller structure like structure 1 and 2 of PID controller (PID1) and structure 2(PID2) were applied and their exhibitions was looked at for an automatic generation control (AGC) system. In [6], Ali and abd-Elazim utilized a BFOA to enhance the PI controller parameters and demonstrated its prevalence over GA in a two-area nonreheat thermal system. In [7] Saroj et al. (2014) exhibited the predominance of Firefly Algorithm tuned PI/PID controller of two area interconnected power system for AGC. In [8] , a modified objective function utilizing integral of time multiplied by absolute value of error(ITAE), damping ratio of prevailing eigen values, and settling time was proposed, where the PI controller parameters are tunes utilized differential evolution(DE) technique and the outcomes were contrasted and the BFOA-and GA-enhanced ITAE-based PI controller to show its prevalence. A hybrid BFOA-PSO strategy was utilized in [10] to tune the PI controller parameters of two-and three area power system. The predominance of BFOA-PSO strategy over PSO, BFOA, GA craziness-based PSO (CRAZYPSO), and adaptive neurofuzzy interence system (ANFIS) has been shown by the authors.

In this study, execution investigation of FA is introduced for tuning parameters of the PI and PID controllers in load frequency control of a single area power system. The structured PI and PID controllers with proposed approach are simulated under step load disturbance conditions and their exhibitions are contrasted and those of conventional ones.

\section{LOAD FREQUENCY CONTROL}

The chief objectives of LFC are to maintain reasonably pretty frequency, to divide the load within generators, and to control the tie-line interchange schedules. A single area power system consists of a governor, a turbine and a generator. System also includes step load change input to the generator. This work mainly related with the controller unit of a single area power system. The block diagram of a single area power system with the controller is shown in Fig.1.

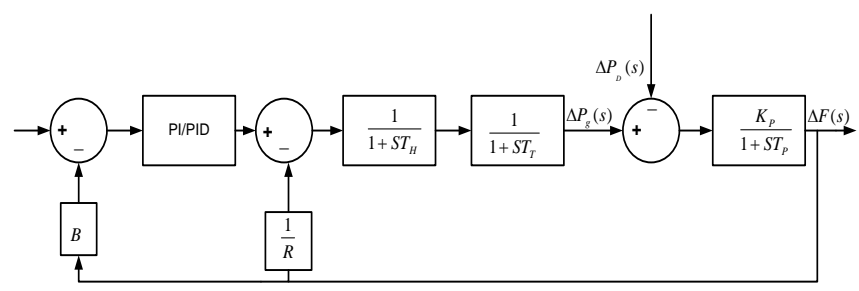

Fig. 1. Transfer function model of single-area non-reheat thermal system

\section{CONTROLLER STRUCTURE AND OBJECTIVE FUNCTION}

To control the frequency PI/PID controller are provided in each area. The structure of the PID controller is show in figure 2 where $K_{p}, K_{i}, K_{d}$, are the proportional, integral \&derivative gains respectively, when used as a PI controller, the derivative path along is removal from figure 2 . 


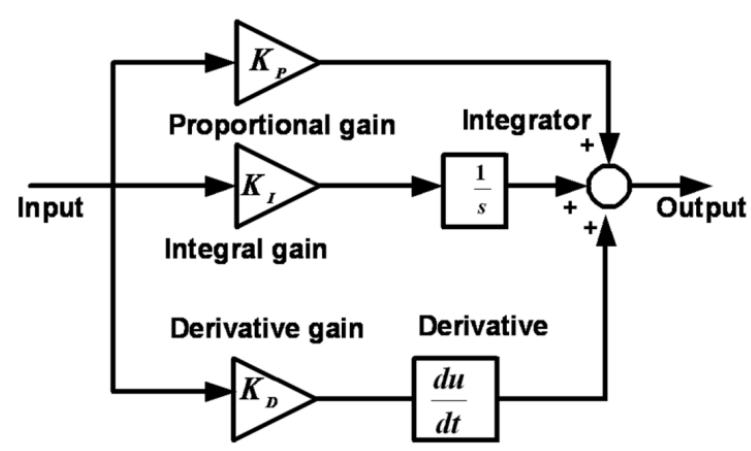

Fig. 2. Block diagram of PID controller structure.

In this work ISE is used as objective function to design the suggested PI/PD controller. The expression for integral square error (ISE) objective function is given in equation (1):

$$
J=I S E=\int_{0}^{t_{\text {sim }}} e^{2} \cdot t \cdot d t
$$

the design problem can be formulated as the following optimization problem.

Minimize J

Subject to

$$
\begin{gathered}
K_{\text {pmin }} \leq K_{p} \leq K_{\text {pmax }}, K_{\text {imin }} \leq K_{i} \leq K_{\text {imax }} \\
K_{d \min } \leq K_{d} \leq K_{d \max }
\end{gathered}
$$

The minimum and maximum values of controller parameters are chosen as [0 2] respectively.

\section{RESULT ANALYSIS}

A single area power system consisting of the speed governor, turbine and generator are shown in Figure 1 is considered. The system is widely used in literature is for the design and analysis of automatic LFC [3]. The suggest FA approach [7] has been applied to determine optimal parameters of the PI and PID controllers. Gains of the PI/PID controllers' parameter are shown in Table 1.

TABLE I. PI/PID CONTROLLER PARAMETER

\begin{tabular}{|l|l|l|l|}
\hline \multicolumn{1}{|c|}{ parameters } & \multicolumn{1}{c|}{$\boldsymbol{K}_{\boldsymbol{p}}$} & \multicolumn{1}{c|}{$\boldsymbol{K}_{\boldsymbol{i}}$} & \multicolumn{1}{c|}{$\boldsymbol{K}_{\boldsymbol{d}}$} \\
\hline Conv: PI [3] & 0.45 & 0.65 & - \\
\hline GSA: PI [3] & 0.6586 & 0.3450 & - \\
\hline FA: PI & 0.6514 & 0.3745 & - \\
\hline GSA: PID [3] & 2.0000 & 1.1820 & 1.3045 \\
\hline FA: PID & 1.9145 & 1.5237 & 1.6750 \\
\hline
\end{tabular}

A $1 \%$ step increase in load demand is applied in area- 1 at $\mathrm{t}=$ $0 \mathrm{sec}$ and the system performance with the PI/PID controller are shown in table 2. It is clear from table 2 that better system performance in terms of ISE objective function, minimum settling times in frequency deviation is achieved with FA tuned PI/PID controller compare to GSA tuned PI/PID and conventional PI controller [3] as mentioned in table 2.
TABLE II. COMPARATIVE PERFORMANCE VALUES FOR $1 \%$ STEP LOAD CHANGE IN AREA-1

\begin{tabular}{|c|c|c|c|}
\hline \multirow{2}{*}{$\begin{array}{c}\text { Techniques/ } \\
\text { parameters }\end{array}$} & $\begin{array}{c}\text { Settling times } \\
\mathbf{2 \%} \text { band) } \mathbf{T S}\end{array}$ & $\begin{array}{c}\text { Peak under } \\
\text { shoot }\end{array}$ & \multirow{2}{*}{$\begin{array}{c}\text { ISE } \\
\times \mathbf{1 0}^{\mathbf{- 4}}\end{array}$} \\
\cline { 2 - 3 } & $\Delta \mathrm{F}$ & $\Delta \mathrm{F}$ & \\
\hline Conv: PI & 0.27 & -0.0195 & 2.3728 \\
\hline GSA: PI & 0.28 & -0.0180 & 2.2680 \\
\hline FA: PI & 0.25 & -0.0180 & 2.1953 \\
\hline GSA: PID & 1.12 & -0.0073 & 0.87961 \\
\hline FA: PID & 0.97 & -0.0063 & 0.70512 \\
\hline
\end{tabular}

A step increase in load of $1 \%$ in area-1 are considered and system dynamic response is shown in figure 3-4. It is clear from figure 3-4 that the best dynamic performance in terms of frequency error deviation and settling time is achieved by FA tuned PI/PID controller compare to the GSA tuned PI/PID controller and conventional PI controller for the single area power system.

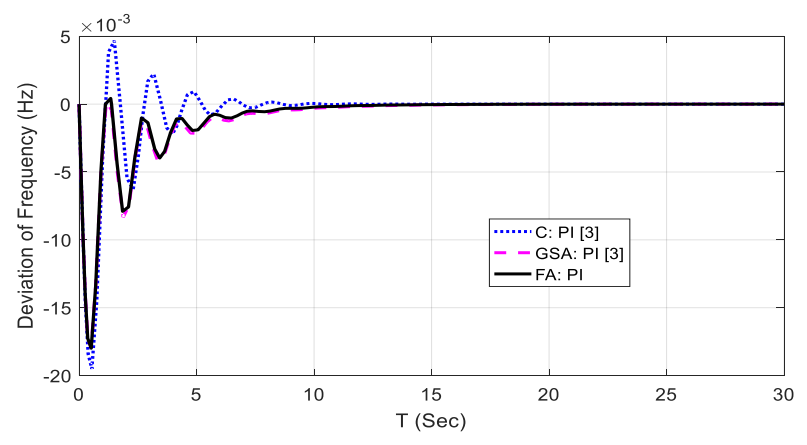

Fig. 3. Change in frequency with $1 \%$ SLP (Conventional: PI, GSA: PI, FA PI)

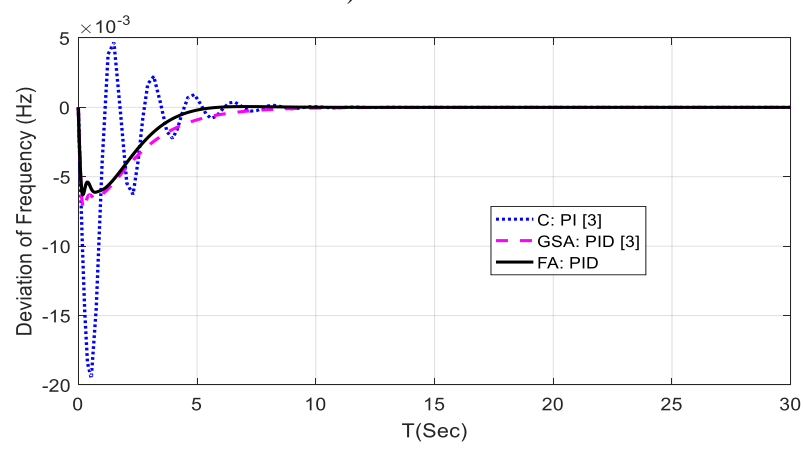

Fig. 4. Change in frequency with $1 \%$ SLP (Conventional: PI, GSA: PID, FA: PID).

\section{SENSITIVITY ANALYSIS}

Sensitivity analysis is performed to study the robustness of the system to wide changes in the system parameters $[7,8,9]$. The speed governor time constant, turbine time constant is changed from their nominal values within the range of $+50 \%$ to $-50 \%$. Deviation in frequency for $1 \%$ change in SLP with these varied conditions are depicted in figure 5-6. It is clear from figure 5-6 that there is negligible effect of the change of system parameter variation. 


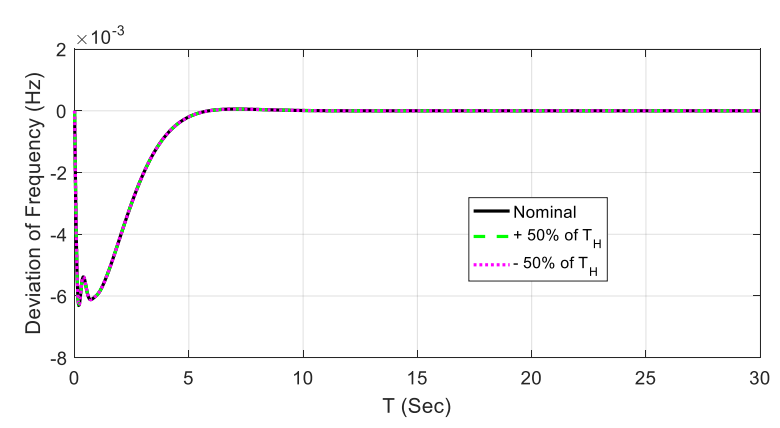

Fig. 5. Deviation in frequency for $1 \%$ change in SLP with variation of $\mathrm{T}_{\mathrm{G}}$.

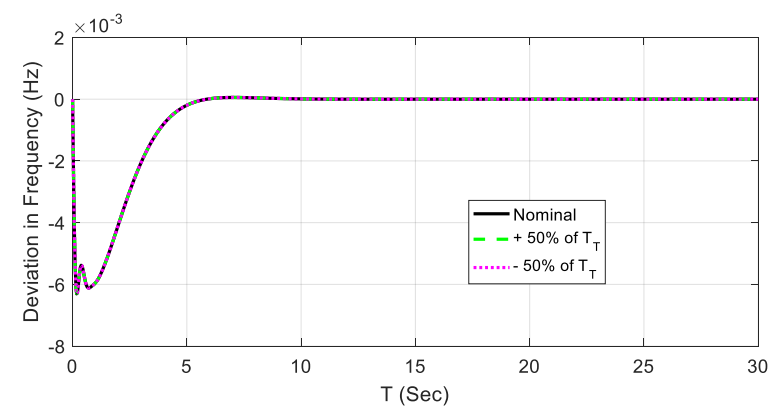

Fig. 6. Deviation in frequency for $1 \%$ change in SLP with variation of $\mathrm{T}_{\mathrm{T}}$.

\section{CONCLUSION}

In this work an attempt has been made to apply firefly algorithm based PID controller for LFC of two area interconnected power system. Simulation results show that better system performance in terms of ISE objective function, minimum settling times in frequency deviation is achieved with FA tuned PI/PID controller compare to GSA tuned PI/PID conventional PI and controller. Lastly sensitivity analysis is carried out by varying the system parameters from their nominal values to elaborate the robustness of the approach. It has the potentiality of implementation in real time environment.

\section{REFERENCES}

[1] O.I. Elgerd, "Electric Energy Systems Theory -An Introduction," New Delhi: Tata McGraw Hill, 2000.

[2] P. Kundur,"Power System Stability and Control," New Delhi: Tata McGraw Hill, (2009).

[3] S. duman, N. yorukeren, and I. H. altas, "Load Frequency Control of a Single Area Power System using Gravitational Search Algorithm," IEEE Conference on Innovations in Intelligent Systems and Applications (INISTA), July 2012.

[4] L.C. Saikia, J. Nanda, and S. Mishra, "Performance comparison of several classical controllers in AGC for multi-area interconnected thermal system," International Journal of Electrical Power \& Energy Systems. Vol. 33, pp.394-401, 2011.

[5] D. Khamari, L. Mishra, S. Sahu, P. Gartia, B. P. Gouda, M. Dash "Automatic generation control of an interconnect power system using modified classical control," Int. journal of Eng. Research and Technology, Vol.6, pp. 303-312, 2017.

[6] E.S. Ali, and S.M. Abd-Elazim, "Bacteria foraging optimization algorithm-based load frequency controller for interconnected power system," International Journal of Electrical Power \& Energy Systems, Vol. 33, pp. 633-638, 2011.

[7] S. Padhan, R. K. Sahu, and S. Panda, "Application of firefly algorithm for load frequency control of multi-area interconnected power system," Elect. Power Comp. and Syst., Vol. 42, pp. 1419-1430, 2014.

[8] U.K.Rout, R.K. Sahu, and S. Panda,"Design and analysis of differential evolution algorithm based automatic generation control for interconnected power system," Ain Shams Engineering Journal, Vol. 4, pp.409-421, 2013.

[9] S. Panda, B. Mohanty, P. K. Hota, "Hybrid BFOA-PSO algorithm for automatic generation control of linear and non-linear interconnected power system,” Appl. Soft Comput., Vol.13, pp.4718-4730,2013.

\section{APPENDIX}

Nominal values of the single area system investigated are [3]

$\mathrm{f}=60 \mathrm{~Hz} ; B==0.425 \mathrm{pu} \mathrm{MW} / \mathrm{Hz} ; \mathrm{R}=2.4 \mathrm{~Hz} / \mathrm{pu} ; T_{G}=0.08 \mathrm{~s} ; T_{T}=0.3 \mathrm{~s}$; $K_{P S}=120 \mathrm{~Hz} / \mathrm{puMW} ; T_{P S}=20 \mathrm{~s}$; 